\title{
Information Integration in a Smart City System-A Case Study on Air Pollution Removal by Green Infrastructure through a Vehicle Smart Routing System
}

\author{
Jules Muvuna ${ }^{1, *} \mathbb{C}$, Tuleen Boutaleb ${ }^{1}{ }^{\mathbb{D}}$, Slobodan B. Mickovski ${ }^{1}{ }^{\mathbb{D}}$, Keith Baker $^{1}$, \\ Ghoreyshi Seyed Mohammad ${ }^{2}$ (D), Mario Cools ${ }^{3}$ and Wissal Selmi ${ }^{3}$ \\ 1 School of Engineering and Built Environment, Glasgow Caledonian University, Cowcaddens Rd, \\ Glasgow G4 0BA, UK; t.boutaleb@gcu.ac.uk (T.B.); slobodan.mickovski@gcu.ac.uk (S.B.M.); \\ keith.baker@gcu.ac.uk (K.B.) \\ 2 Mathematical Sciences, University of Southampton, University Road, Southampton SO17 1BJ, UK; \\ S.M.Ghoreyshi@soton.ac.uk \\ 3 Urban and Environmental Engineering Department, University of Liège, Local Environment Management \& \\ Analysis (LEMA), Allée de la Découverte9, Quartier Polytech 1, BE-4000 Liège, Belgium; \\ mario.cools@uliege.be (M.C.); wissal.selmi@uliege.be (W.S.) \\ * Correspondence: Jules.Muvuna@gcu.ac.uk
}

Received: 12 May 2020; Accepted: 20 June 2020; Published: 23 June 2020

\begin{abstract}
Over the past few years, the "smart city" concept has emerged as a new trend to answer challenging issues related to urban development. Transformation of a city system into a smart system is meant to improve the quality of life for its people and their way of living, its environment, economy, transport, and governance. Due to benefits associated with the concept of the smart city and associated implementation challenges, traditional city systems have been undergoing transformation into smart city systems. However, observed approaches of transformation presented disconnected and fragmented city systems that usually hamper the interaction of city subsystems with the efficient and environmentally friendly urban environment. This work emphasizes the systematic view of a city system and proposes a novel method of smart city system integration. The results of our study show that in a smart city environment, where ecosystem services are valorised, air pollution emitted by vehicles can be removed by taking into consideration information related to air pollution reduction. A case study is presented to demonstrate that, with an integrated system, information outputs on travel decisions are different and more valuable. The case study explores the operability of the system, its limitations, and potential future improvements.
\end{abstract}

Keywords: smart city; information integration; air pollution; vehicle smart routing

\section{Introduction}

Observed rapid urbanisation and projected increases in urban populations in cities around the world motivate city planners and policy makers to consider how to sustainably manage resources in an environment that meets urban population needs. Based on [1], 54\% of the global population lives in urban areas. In Europe, up to $75 \%$ of the continent's population live in urban areas, and these numbers are expected to reach $80 \%$ by the end of 2020 [2]. We have entered an urban era where cities around the globe are being challenged by rapid urbanisation and there has been an increasing awareness of problems related to the environment and sustainable urban development.

Fuelled by the development of technology, the concept of a "smart city" has taken over as a solution to challenges faced by cities. Although this concept is still criticised as too techno-centric [3] and 
lacks proper conceptualisation [4], its popularity has not stopped growing with combined objectives of enhancing the quality of life, Information and Communications Technology (ICT) development in urban areas, adopting new ways of governance, and concentration on sustainable development and human capital [4]. A smart city concept comes together with more analogous terms, such as virtual city, intelligent city, ubiquitous city, knowledge city, etc.-all of which were blamed for lacking a "people" component [2]. The smart city system also has many definitions [2,4] and appears not to have a one-size-fits-all definition. This highlights its complexity as a system with six subsystems. Dirks \& Keeling [5] stressed the need for an integrated city's subsystems in creating a smart city, and the idea was supported by Moss Kanter \& Litow [6], who argued that a smart city will not be created by infusing technology in subsystems one by one but that the city should be treated as a whole entity. Some work separated the concept into numerous features with the complexity to manage a city in a holistic way $[7,8]$. From a technology perspective, the smart city concept is mostly built on ICT, and the concept is seen like a winning strategy to achieve urban sustainable development, to meet the need of citizens, and to preserve the environment [9].

The application of the smart city concept is still fragmented and requires integration of all subsystems $[2,5,6,10,11]$. Some authors [12] observed a lack of an integrating view with regards to transforming traditional cities into smart cities. They also noticed that the way the smart city concept is approached presents disconnection of the subsystems. In an effort to develop a method for an integrated smart city system, some researchers [11] (see Figure 1) focused on an information perspective of the smart city concept.

This work builds on an integrative line of inquiry to propose a scenario that highlights and tests a new approach of information integration in a smart city. The core objective of this work is to provide a viable solution to the prevailing integration issue observed in the process of transformation of traditional city systems into smart city systems. Through a case study, this work introduces a novel vehicle smart routing system to highlight the integration approach, an approach that maximises the benefits of completeness of information. The work stresses the benefit of an integrated smart city system and presents a novel approach to how such an integrated system would function subject to a particular scenario. The focus is directed to smart mobility and smart environment, two subsystems of a smart city system that deal with pollution in the urban environment. We are in an era in which environmental concern is high for many, and the least cost path problem is of interest in a variety of areas, especially when analysing issues related to traffic. Given that road traffic is one of the major air pollution contributors [13], the relevant parts of a smart environment subsystem are considered, which will direct the focus on green infrastructure and its potential to reduce air pollution. It is obvious that the integrative approach must have a holistic vision integrating all components, but in the context of this study, the work wishes to test the integration of two specific components of a smart city system and therefore takes as a starting point the point where information from mobility and environment can work together to inform citizens. In a smart city environment, travellers are proposed routes which would rather minimize the footprint of their travel on the environment. To achieve this, the proposed system presents an option of a route that has higher capacity to remove air pollution to travellers seeking a route. This practice not only displays an integrated smart city system but also highlights the possibility to travel with less impact on the environment since it is helped by green infrastructure in a smart city environment.

\section{Background}

It was observed that with eco-routing, adopted approaches in previous work focused on reduction of fuel consumption [14-16] by proposing routes that would optimise energy consumption and emissions. In this work, we agree that the eco-routing practice has potential to reduce fuel consumption and harmful pollutants generated by mobility; however, we also believe that there is a necessity to remove emitted pollutants from the air. One limitation of our approach may be that we only consider the air pollution removal aspects of the vegetation cover; nonetheless, we acknowledge that the tree 
cover at route scale provides many other ecosystem services like temperature reduction, shading, amenities, etc. [17,18].

\subsection{Air Pollution Removal by Trees in a Smart Environment}

The removal of particulate matter and other air pollutants is an ecosystem service offered by vegetation and green infrastructure. They can absorb gaseous pollutants through their stromata and intercept particulate matter on their surfaces. The work presented here focuses on trees since they can provide greater pollution removal potential [19], especially in proximity to the road environment $(<50 \mathrm{~m}$; [13]), where concentration of air pollution from traffic vehicles is the highest [13]. Therefore, this study considers this distance and makes reference to [20] to quantify the capacity of a route to remove air pollution.

\subsection{Smart Routing in Support of Air Pollution Removal}

More than $60 \%$ of the European population lives in an urban area [21]. Mobility challenges in actual urban areas are generally affected by increased travel times due to congestion, which increases fuel consumption and pollutant emissions [15]. Cities always try to find responses to congestion and air pollution by improving vehicles and making travel more efficient. There are now many tools that advise travellers of the efficient routes to take to reduce the duration of travel. These tools generally use a global positioning system (GPS) and mapping-routing software, vehicle speeds on different roadways, and real time traffic information-to advise a least cost path to a particular destination. A "least cost path" in general means a path that minimises emissions. Efforts have been made to develop eco-routing navigation systems to minimise fuel consumption and emissions [14-16]. However, although in some cases the shortest distance takes the shortest time and minimum fuel consumption, it has been argued that shortest distance does not always imply shortest travel time and that the least polluting route was not always the fastest route due to factors such as congestion [15]. This was explained by [22], who highlighted a nonlinear relationship between travel speed and vehicle fuel consumption and emissions. There has been a big focus on how to minimize vehicle fuel consumption/emissions [14].

Many approaches that attempt to minimise traffic emissions through eco-routing can be found in the literature and all these approaches try to reduce air pollution by minimising energy consumption [14-16,23]. However, more can be done not only to minimise emission and air pollution but also to use green components to reduce air pollution. This work closes this gap by presenting a smart city system that favours information integration. This practice consists of integrating information from all the subsystems of a smart city system to get a comprehensive set of information as shown in Figure 1.

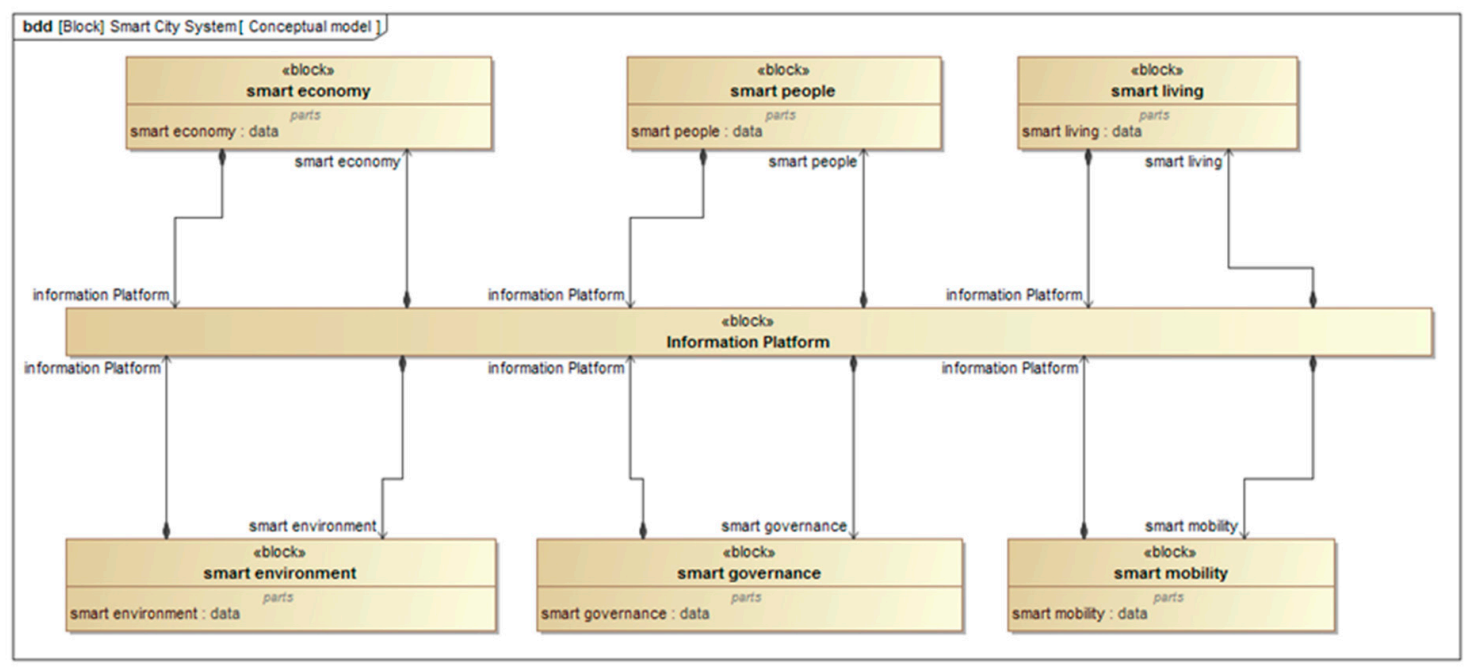

Figure 1. Conceptual structure of an integrated smart city system (Adapted: [24]). 
There is evidence of a growing demand for both system integration of the smart city system and solutions to deal with pollution generated by traffic [25]. This work proposes a solution that is helped by combined information in a smart city on green infrastructure and vehicle smart routing to contribute to air pollution removal from the air. Although actions such as carpooling, electric vehicles (EVs), autonomous vehicles (AVs), and others such as eco-routing can minimise automobiles' fuel combustion and reduce air pollution, it is also essential to extract these harmful pollutants from the air for the benefit of all green infrastructure users.

\section{Materials and Methods}

This section elaborates the adopted vehicle smart routing system approach, a system that integrates information to enhance its significance. It combines air pollution removal by trees and builds on current vehicle routing practices to present a new perspective on vehicle routing systems that considers information integration in a smart city system.

\subsection{Working Approach}

The approach towards the new proposed vehicle smart routing system is presented in Figure 2. Often, a review of literature presents eco-routing navigation systems that could minimise pollution emitted but that does not remove it. The approach in this work is to provide integrated information about the potential of trees to reduce air pollution through smart routing. A combination of route characteristics and green infrastructure produces a smart routing system that rather valorises air pollution removal by green infrastructures.

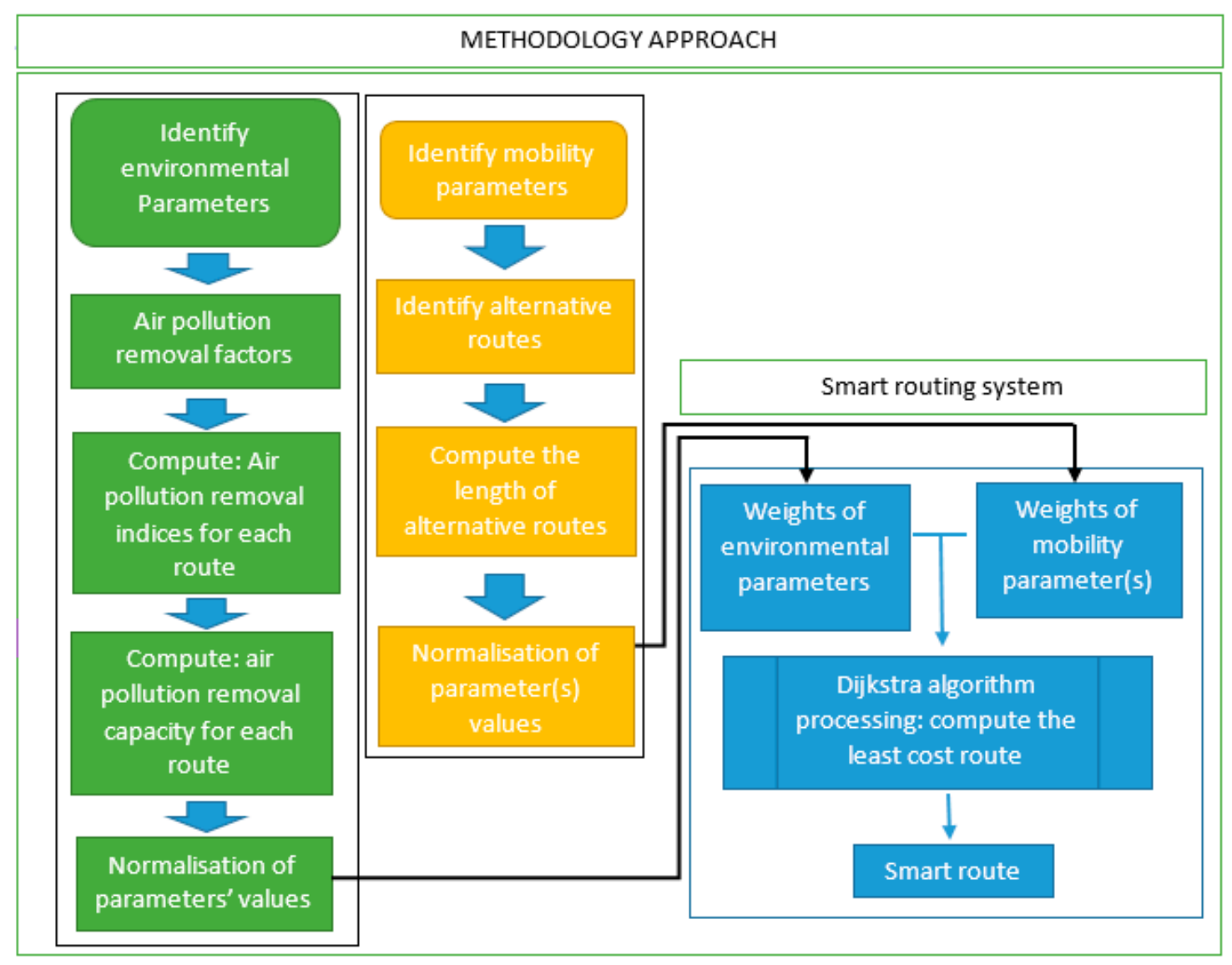

Figure 2. Vehicle smart routing system workflow.

Three tasks are performed in Figure 2, where processing of environmental information is presented in green and mobility information processing is presented in yellow. Both green and yellow column 
results, after processing, give weights with which the smart routing system combines to identify the least cost route (presented in blue). With a weighted graph (Figure 3), an algorithm will compute a smart route to be advised to travellers who are frequently faced by the problem of finding the least cost route while planning their trips.

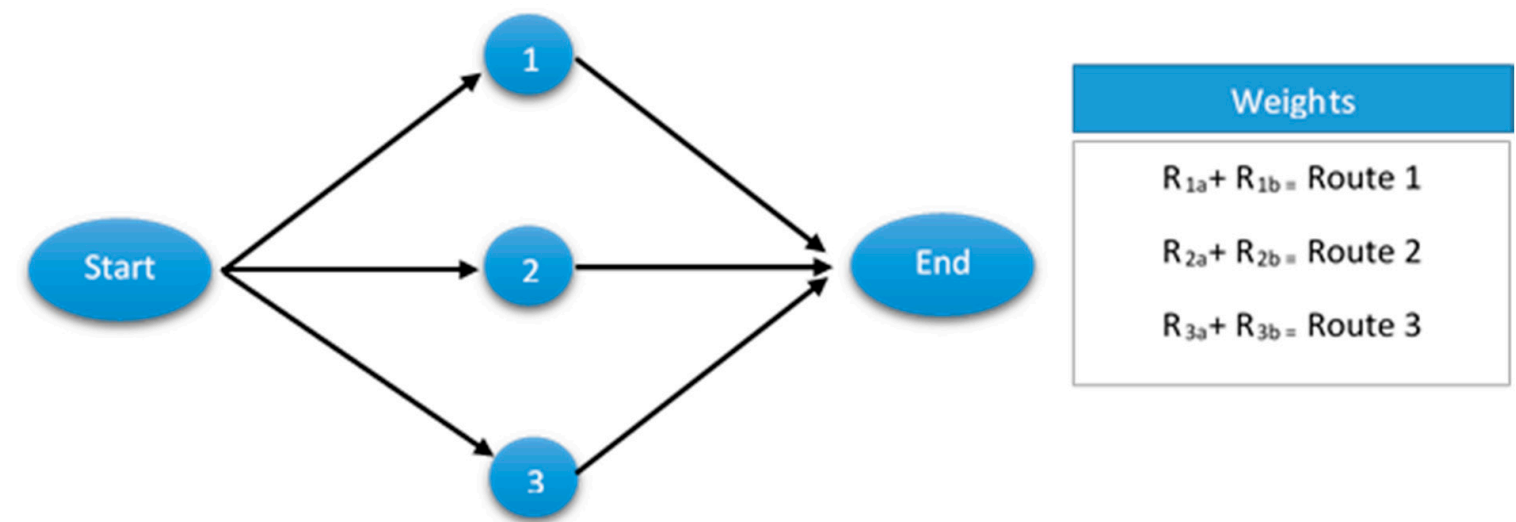

Figure 3. Representation of alternative route on a weighted graph.

\subsection{Study Area}

Strasbourg, a city located in northeast of France on the border with Germany, was the study area for this work due to the availability of robust and relevant datasets. It is the largest city and capital city of the Grand Est region. It was estimated that, in the city of Strasbourg, commuting trips produced up to $629.23 \mathrm{~kg}$ per commuter per year of carbon dioxide. This required 28.90 trees for each passenger to compensate for carbon dioxide production [26].

\subsection{Data Used}

To perform quantification of air pollutants removed by trees while following a particular route, there was a need for green infrastructure and mobility data for such a task and air pollution reduction rates computed in [20]. Vegetation (i.e., tree cover) data were obtained from Open Data Grand East official website (accessed in January 2020). More data concerning environmental parameters were obtained making reference to [20]. For mobility data, distances between points were obtained through analysis in ArcGIS.

\subsection{Air Pollution Removal}

The reduction of air pollution, which is an ecosystem service produced locally by vegetation, was included in this study. Following the literature [19,27], the assessment of this service at a local scale was based on an up-down approach crossing spatial data (i.e., tree cover) extracted for our route sample and data from place-specific literature to quantify the total amount of air pollution removal per route.

A study by Selmi et al. [20] performed air pollution removal quantification where, in a period of non-precipitation, an i-Tree Eco model dry deposition module [26,27] was used to estimate the removal rate of air pollutants. The i-Tree Eco dry deposition module was used to estimate pollution removal throughout the year and determined reduction rates of air pollutants by trees as follows: $\mathrm{NO}_{2}: 0.92 \mathrm{~g}$ $\mathrm{m}^{-2}$ of tree cover year ${ }^{-1}, \mathrm{O}_{3}: 3.73 \mathrm{~g} \mathrm{~m}^{-2}$ of tree cover year ${ }^{-1}, \mathrm{PM}_{10}$ course: $0.79 \mathrm{~g} \mathrm{~m}^{-2}$ of tree cover year ${ }^{-1}$, and $\mathrm{PM}_{2.5}: 0.3 \mathrm{~g} \mathrm{~m}^{-2}$ of tree cover year ${ }^{-1}$. These reduction rates were used for this work as they were obtained in the same context as the study area. A start and end point were selected randomly in the study area to represent an origin and a destination, which allowed for the identification of possible and relevant alternative routes. In general, route network navigation tools are digital maps of routes created in a Geographic Information System database in which user interfaces allow users to input 
origin and destination information to find a route. In reference to [15], and given that the main objective of this work is more integration of information in a smart city rather than the development of a routing system, random selection of origin and destination information was found acceptable. In ArcGIS, a buffer zone was elected within the near road environment $(<50 \mathrm{~m})$, and vegetation cover could be obtained for each route, which represented the canopy cover. The canopy cover and air pollution reduction indices allowed to compute air pollution reduction capacity for routes (Equation (1)).

$$
C_{r}=E_{i} * C_{c r}
$$

where $C_{r}$ is the capacity of a particular route to remove air pollution, $E_{i}$ is reduction indices for specific pollutant, and $C_{c r}$ is the canopy cover of an individual route (r).

Since air pollution removal quantification was based on place-specific literature, no information was found about air pollution removal by species in Strasbourg city. We were limited to reduction rates assessed within Strasbourg city, like it has been done in New York and Melbourne [19,27].

\subsection{Smart Routing in an Integrated Smart City}

The development of the system model of the smart routing system (Figure 4) make reference to Figure 2. It shows the flow of information in a smart city system where external sources associated with specific smart subsystems fetch and feed-in specific data, mobility and environmental data in the case of this study, to be processed into meaningful information and later combined at the level of the smart routing system to assign a route.

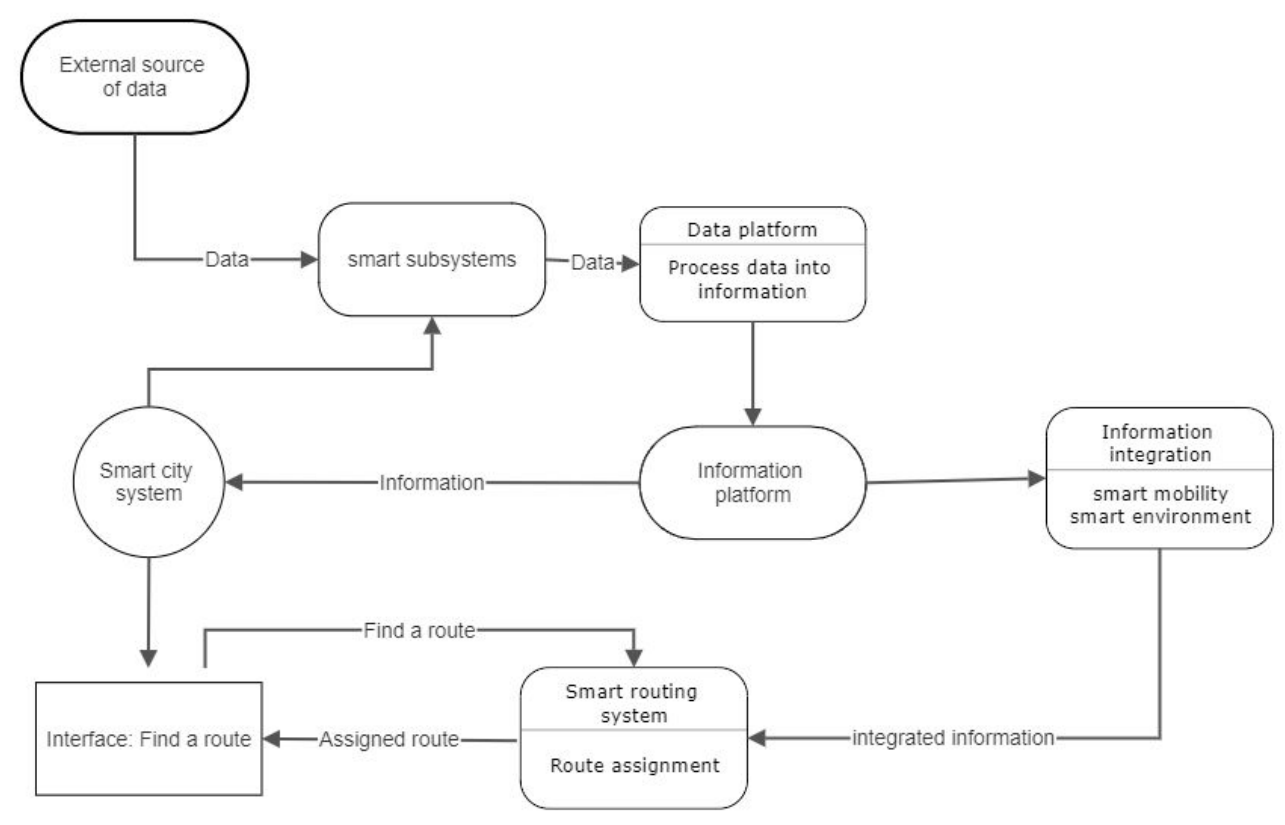

Figure 4. System model of the smart routing system.

Various algorithms such as Bellman-Ford algorithm, the Floyd-Warshall algorithm and the Dijkstra algorithm, among others, can be used for calculation of the least cost route [28]. In this work, the Dijkstra algorithm is used to compute the least cost path in a set of alternative paths [28]. This algorithm was considered for this work because, in addition to being the most used in vehicle routing and other network connection protocol, it is easily implemented in a distributed way, and its results contain information on vertices of the entire network, not only vertices they are connected to $[28,29]$. Traffic problems are dynamic and can change rapidly. This algorithm enables us to compute shortest paths to all destinations from a source instead of just for a specific pair of source and destination nodes at a time, which is very useful in our problem, especially for the complex routes. Provided with 
good data, the Dijkstra algorithm can be useful for analysing a least cost past problem and proposing a solution (Figure 5). The Dijkstra algorithm cannot accept a multigraph (which is permitted to have multiple edges or parallel edges between the same end nodes). Without loss of generality, to solve this problem, the multigraph is converted to a simple graph, which is an acceptable input format for the Dijkstra algorithm, by adding the virtual nodes (showing different route options) between the source and destination. This conversion can be done on any graph input with multiple nodes to find the optimal solution with a lower computing time. In the Dijkstra algorithm, a weighted graph with a source node (start), the algorithm computes the least cost path to a destination node (end) (Figure 3).

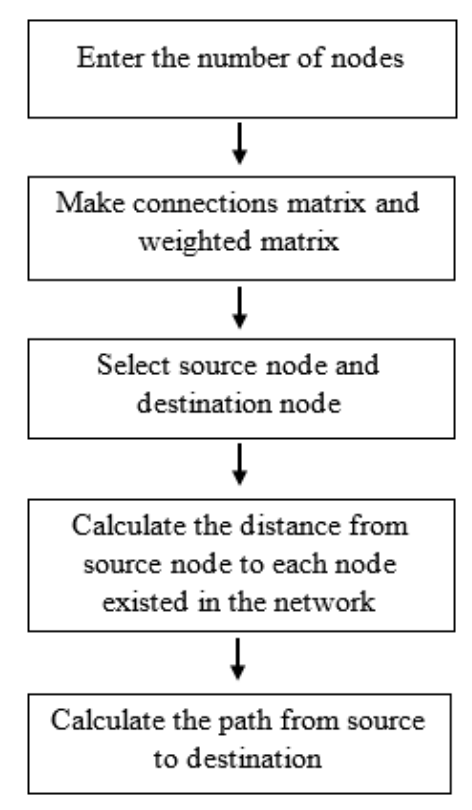

Figure 5. The Dijkstra algorithm flowchart (source: [30]).

Considering the case in which there is a presence of more than one parameter, which is the case for this work, the same algorithm can be used to compute the least-cost route in a set of alternative paths taking into consideration all parameters. This work proposed a combination of mobility and environmental parameters to support decisions on the least cost route in an integrated smart city environment. This definitely plays an important role on choices made by a traveller while navigating on transportation road networks. Users of the transportation network have preferences such as avoiding toll roads, long travel time, etc. [15]. Generally, path construction considers a number of vertices in a graph, and finding the least cost route can take numerous inputs based on minimisation criteria such as travel time, distance, fuel consumption, emission, etc. In the case of this work, path construction is based on removal of air pollutants (i.e., $\mathrm{CO}, \mathrm{NO}_{2}, \mathrm{O}_{3}, \mathrm{PM}_{10 \text { coarse, }}$ and $\mathrm{PM}_{2.5}$ ) and the shortest route in terms of distance. The overall functionality of information integration combines a general routing navigation practice that considers the shortest path and green infrastructure to advice travellers of a smart route from a network, calculated through a weighted graph representing a network of routes. Weights show the capacity for each individual route to remove air pollution. The principle is that by integrating characteristics of routes and green infrastructure information, air pollution produced by vehicles is removed from the air by green infrastructures. Normalisation of values was performed using Equation (2) to enable combination of mobility parameters and environmental parameters and generate a weight for each individual route, which in turn allows integrated information to be obtained. In this work, the least cost route has the highest capacity to remove pollutant from the air.

$$
x_{E n v}^{\prime}=\frac{x_{i j}}{x_{j}^{m a x}} \text { and } x_{M o b}^{\prime}=\frac{x_{j}^{\min }}{x_{i j}}
$$


where $x_{E n v}^{\prime}$ and $x_{M o b}^{\prime}$ are environmental and mobility parameters, respectively, $x_{i j}$ is the particular value of a parameter, and $x_{j}^{\max }$ and $x_{j}^{\min }$ are maximum and minimum values of each type of parameter, respectively.

After the environmental and mobility parameters are normalized, a route cost can be calculated by summing up the weighted normalized parameters as follows:

$$
R_{i}=\sum_{j=1}^{N} w_{j} \mathbf{x}_{i j}
$$

where $w_{j}$ is the weight of the $j$ th parameter. In a multi-objective function, the weight of each parameter can be set by users based on their preferences. Thus, the weight of influential parameters can vary in different applications. As the proposed approach is more interested in environment-friendly routes, we have decided to consider the same influence in our proposed approach. However, if the number of additional pollutants parameters increases in a way that the impact of the distance becomes less, the distance weight can be increased to compensate for this.

Environmental data/vegetation data were analysed using ArcMap, a component of ArcGIS tool, to draw a buffer zone (shown in Figures 6 and 7).

\section{Results and Discussion}

\subsection{Results}

Information shown in Figures 6 and 7 illustrates the study area and the routes, subjects of this study. Constructed buffer zones shown in Figure 7 allowed us to obtain the canopy cove for computation of tree cover, and the results are shown in Table 1, together with the length of each route.

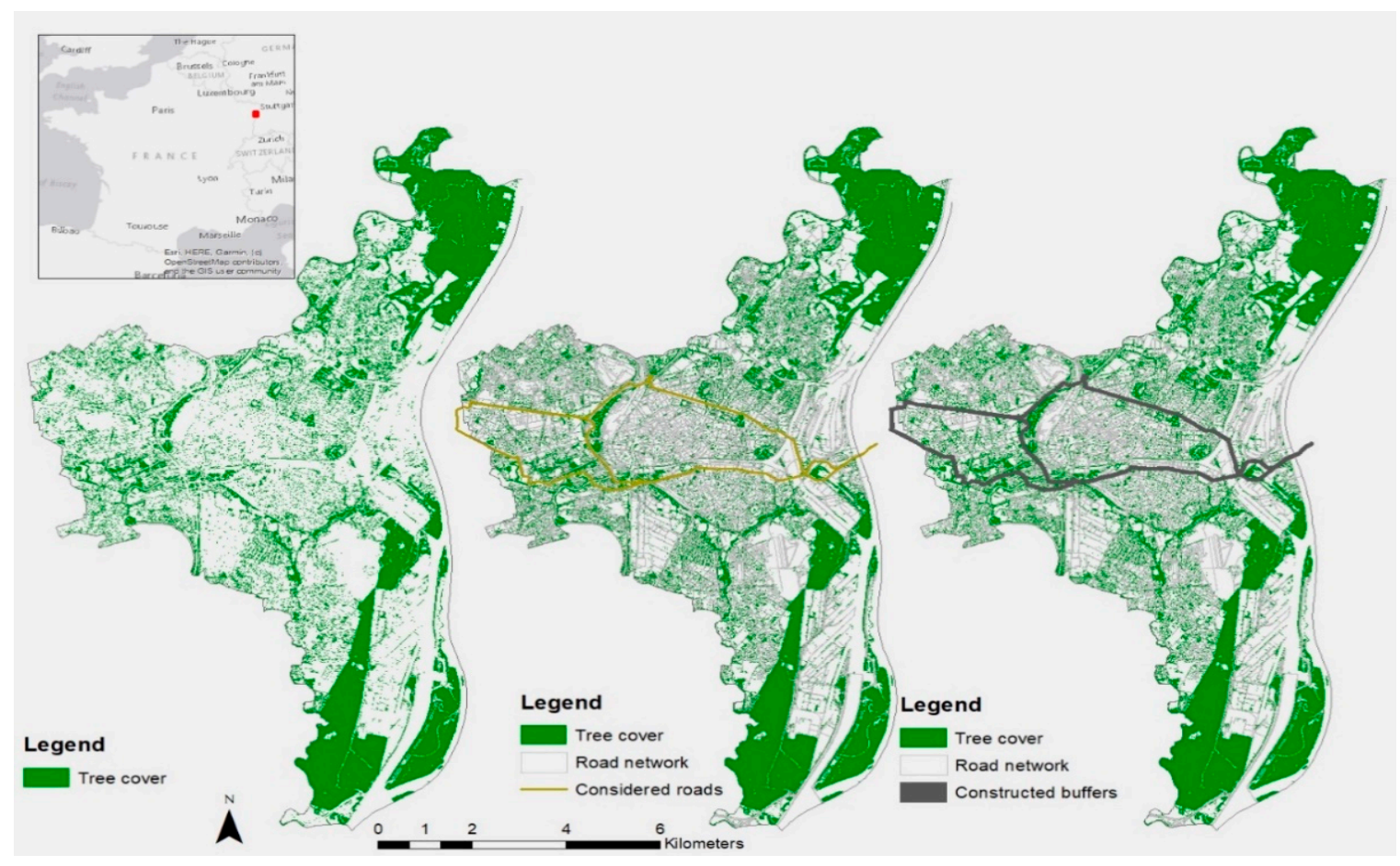

Figure 6. Representation of the studied area, considered routes, and constructed buffers. 


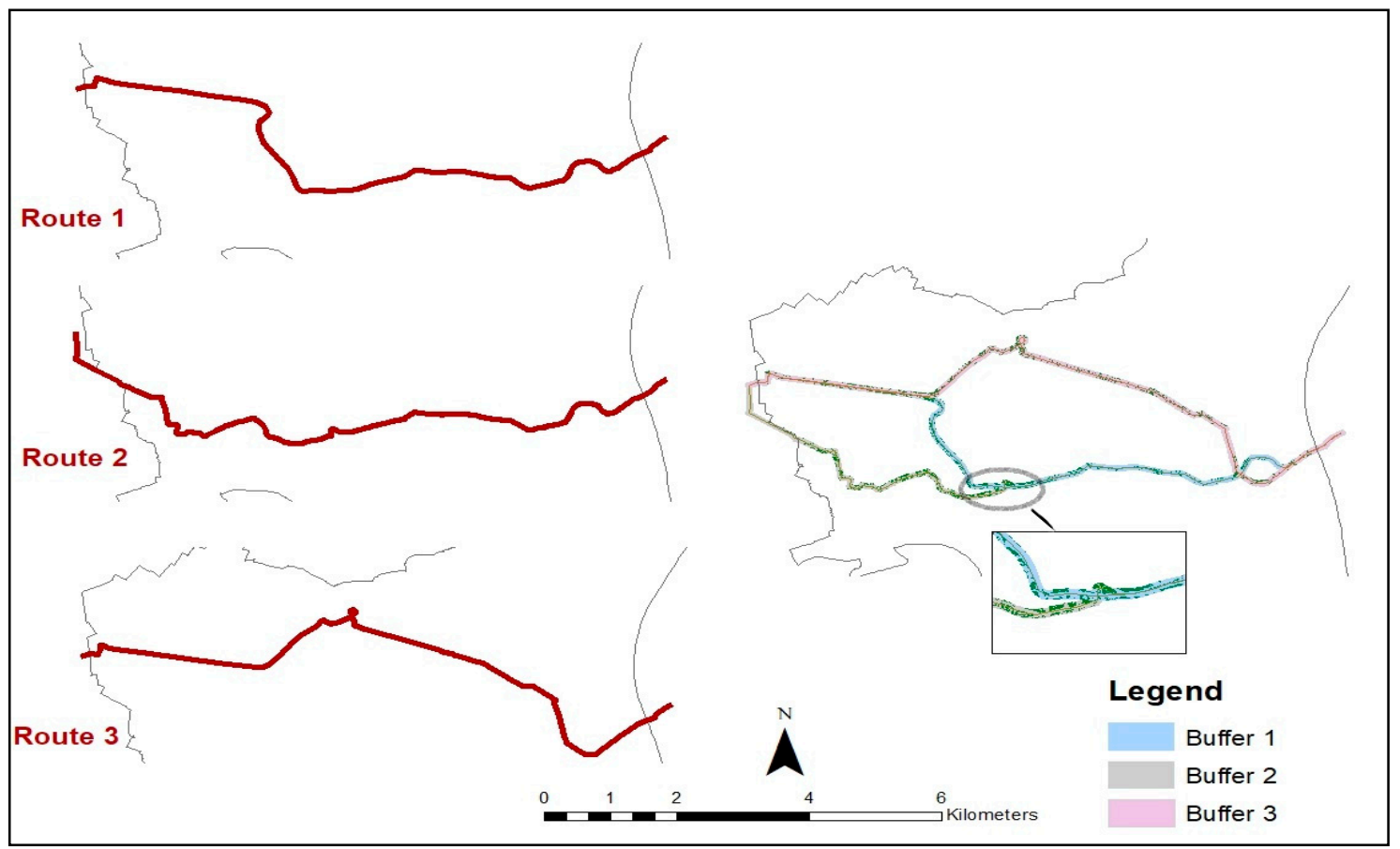

Figure 7. Identification of considered routes and a zoom in on constructed buffers.

Table 1. Routes length and corresponding canopy cover.

\begin{tabular}{ccc}
\hline Routes & Length_(km) & Tree Cover $\left.\mathbf{( m}^{2}\right)$ \\
\hline Route 1 & 10.98 & $203,797.25$ \\
Route 2 & 11.25 & $202,623.57$ \\
Route 3 & 11.26 & $206,412.08$ \\
\hline
\end{tabular}

Making use of air pollution reduction factors in [20], removal indices were obtained as shown in Table 2. The capacity of tree cover to remove air pollution for each route was computed (Equation (1)), helped by vegetation data as shown in Table 3 in the next section.

Table 2. Indices of air pollution removal by trees (Source, [20]).

\begin{tabular}{cccccc}
\hline \multicolumn{7}{c}{ Removal Indices $\left(\mathrm{g} \mathrm{m}^{-\mathbf{2}}\right.$ of Tree Cover Year $\left.^{-\mathbf{1}}\right)$} \\
\hline $\mathrm{CO}$ & $\mathrm{O}_{3}$ & $\mathrm{NO}_{\mathbf{2}}$ & $\mathbf{P M}_{10}$ COARSE & $\mathbf{P M}_{\mathbf{2 5}}$ & $\mathrm{SO}_{2}$ \\
0.08 & 3.73 & 0.92 & 0.79 & 0.3 & 0.07 \\
\hline
\end{tabular}

Table 3. Air pollution removal by trees.

\begin{tabular}{ccccccc}
\hline & \multicolumn{6}{c}{ Pollution Removal (g Year ${ }^{-1}$ per Trip) } \\
\cline { 2 - 7 } & CO & $\mathbf{O}_{3}$ & NO $_{2}$ & PM10 COARSE & PM25 & SO2 \\
\hline Route 1 & $16,303.78$ & $760,163.74$ & $187,493.47$ & $160,999.83$ & $61,139.18$ & $14,265.81$ \\
Route 2 & $16,209.89$ & $755,785.92$ & $186,413.68$ & $160,072.62$ & $60,787.07$ & $14,183.65$ \\
Route 3 & $16,512.97$ & $769,917.06$ & $189,899.11$ & $163,065.54$ & $61,923.62$ & $14,448.85$ \\
\hline
\end{tabular}

The weights presented in Table 4 are the results of normalisation. The computation made use of Equation (2) and each route associated with its individual weights with which the Dijkstra algorithm uses a weighted graph to compute the least cost route with a smart routing system. 
Table 4. Values after parameters normalisation and obtain weights of routes.

\begin{tabular}{ccccccccc}
\hline & \multicolumn{7}{c}{ Data Normalization } \\
\cline { 2 - 9 } & $\mathbf{C O}$ & $\mathbf{O}_{\mathbf{3}}$ & $\mathbf{N O}_{\mathbf{2}}$ & $\mathbf{P M}_{\text {10COARSE }}$ & $\mathbf{P M}_{\mathbf{2 5}}$ & $\mathbf{S O}_{\mathbf{2}}$ & Length km & Weight \\
\hline Route 1 & 0.98733 & 0.98733 & 0.98733 & 0.98733 & 0.98733 & 0.98733 & 1.00000 & 6.92399 \\
Route 2 & 0.98165 & 0.98165 & 0.98165 & 0.98165 & 0.98165 & 0.98165 & 0.97600 & 6.86590 \\
Route 3 & 1.00000 & 1.00000 & 1.00000 & 1.00000 & 1.00000 & 1.00000 & 0.97513 & 6.97513 \\
\hline
\end{tabular}

Therefore, by making use of weights computed in Table 4, the proposed smart routing system would select route 3, as can be seen in Figure 8.

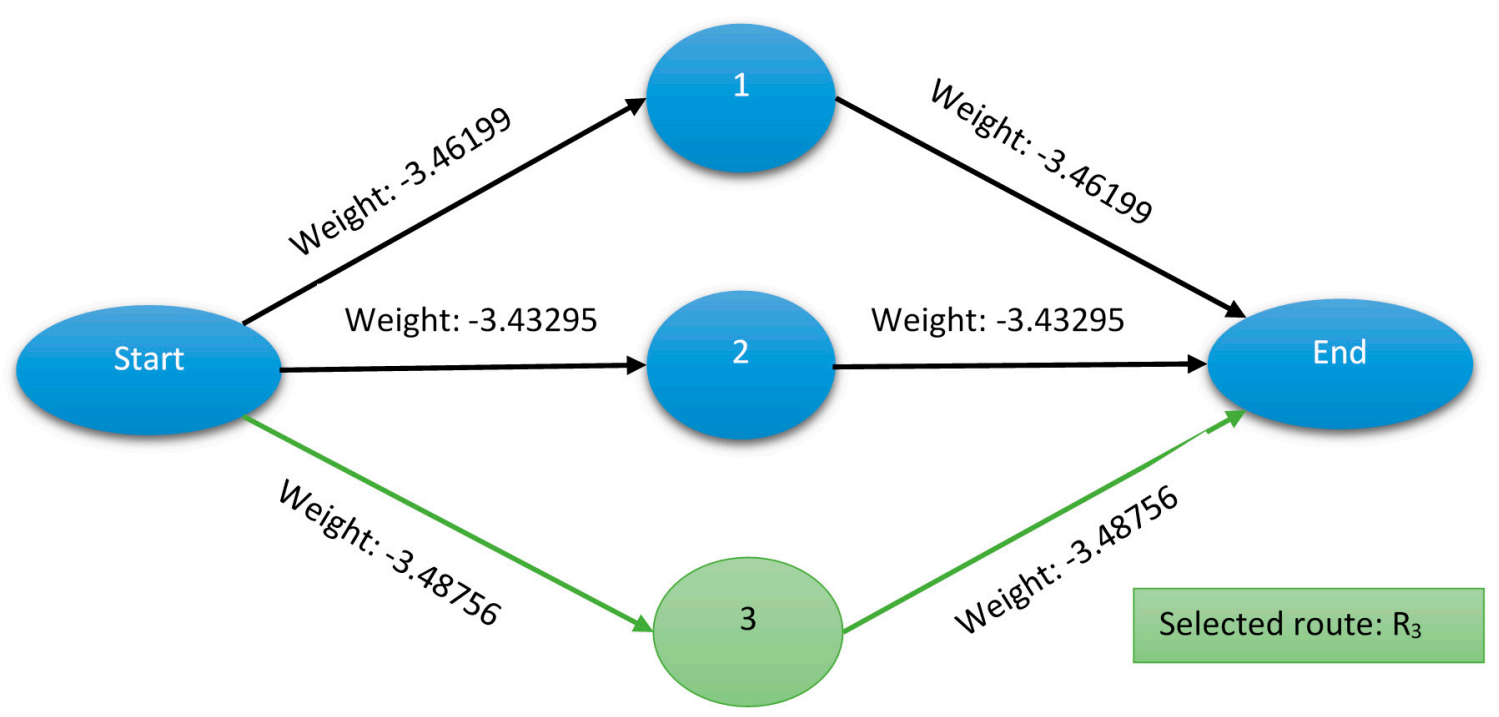

Figure 8. Route selected by the smart routing system.

To make our problem solvable by the Dijkstra algorithm, the initial multigraph (which is permitted to have multiple edges or parallel edges between pairs) needs to be converted to a simple graph without parallel edges. To do this, the virtual nodes can be added as representing the route options while the weight can be divided by two. As the Dijkstra algorithm always finds the path with the shortest value between the source and destination, while we are interested in finding the path with the highest value (higher pollution removal), the values of the edges can be converted to negative to find the correct solution. This approach can be applied to any directed acyclic graph where no negative cycles can be created. Note that the longest path between two given vertices in a weighted graph $G$ (directed acyclic graph) is the same as a shortest path in a graph $-G$, which is derived from $G$ by changing every weight to its negation. Therefore, if shortest paths can be found in $-G$, then longest paths can also be found in $\mathrm{G}$. If $\mathrm{G}$ is a directed acyclic graph, then no negative cycles can be created, and a longest path in $G$ can be found in linear time by applying a linear time algorithm for shortest paths in $-\mathrm{G}$, which is also a directed acyclic graph.

\subsection{Discussion}

Sections 1 and 2 showed that, with smart mobility, one of the six subsystems of a smart city system, a lot of work has been done on the mobility of the future (autonomous vehicles, intelligent traffic management, etc). Road traffic is one of the major sources of air pollution and imposes a heavy cost on health and environment. Green infrastructure (urban trees in our case), as an integral part of the smart environment [31], plays an important role in cleaning the air we breathe, and urban trees are one potential solution, among others, to help mitigate air pollution depending on tree cover. 
This work explored general practices of smart city development and noted that significant work has been done to enable a better understanding of the smart city concept but also observed that existing approaches on the smart city system lacked an integrative view and linkage in architecture [25]. It presented an integrative method that highlights information integration, albeit with extent limited to the focus of this study, in a smart city system which brings mobility information and environmental information to work together and inform citizens.

Green infrastructure is a complementary and sustainable solution to reduce air pollution. Therefore, green infrastructure associated with other integrative strategy measures, such as vehicle smart routing system, can make a significant positive impact on the environment. However, a green road still does not mean a road with less pollutants. Indeed, the morphology of the streets and the leaf density influence (positively or negatively) the nature of the impact of trees on pollution. Trees can also limit pollutant dispersion and thus increase local pollutant concentrations (e.g., near roadways) [32,33], which could exacerbate public health problems due to air pollution exposure. Integrating the impact of trees on air pollution into traffic management systems should be based on in-depth studies of the interactions between urban morphology and the type of vegetation layer. Besides, other indicators, such as vegetation type, age, and condition [34,35], should be taken into account to ensure drivers and the general public's safety.

From information in Table 1, it is obvious that, if only mobility parameter(s) (distance) is considered, route $1\left(R_{1}\right)$ would be selected as the least cost route given that it has the smallest weight. In this case, it is worth noting that for mobility parameters, higher values are non-beneficial, and therefore a route with the lowest associated weight is selected. However, in a smart routing system, where both mobility and environmental parameters were to be integrated (as shown in Table 4), the result would be different with a selection of $R_{3}$. However, for environmental parameters in this work, the higher capacity a route has to remove pollution from the air, the more it is beneficial and considered.

In general, travellers look for either the fastest route or the shortest route with an objective of travel time minimisation. It is worth noting that, in vehicle eco-routing systems, though in some cases shortest distance minimises emissions, it does not always procure the shortest travel time. This is the same case for smart routing and can sometimes present constricting solutions. Taking a smart route that maximises removal of air pollution from the air does not always guarantee the shortest route or shortest travel time. Results in Table 1 and Figure 8 expose these facts. If consideration is only given to distance to be travelled, then $R_{1}$ is the route to be chosen in contrary to $R_{3}$, which is chosen by considering both mobility and environmental parameters.

While the presented solution in this work allows for the removal of air pollution from the air, under certain conditions such as peak times, incidents on road networks, and work on road networks, a side effect of the proposed solution could be that more vehicles are directed in areas such as residential areas, which could have an impact on the already existing concern about air pollution effects on public health. Therefore, the routing engine which contains the shortest path algorithm should give the people's dimension of a smart city a special consideration to make sure that the system works for people and improves people's lives. Integration of traffic information and green infrastructure in the process of making smart routing systems can be used to make trips by taking into consideration information on the local environment. It is no doubt that smart routing would require real time data to be richer and more efficient. Real time information is the most efficient and reliable way to determine the least cost route, and it is consistent with [28] with regards to determining the fastest route. Highlighting one of the limitations of this research, the least cost path can only be efficiently determined using real time information.

Given that we did not have access to real time data, future work will enhance the smart routing system presented in this work by considering real time information to give a more reliable route.

Our approach integrating traffic information and green infrastructure relied on data availability and the objective of testing the integration of one ecosystem service information in the routing-system. In this context, the potential of trees to provide ecosystem services (or one ecosystem service in our 
case) is a tool and does not present an outcome. However, we recognize the necessity to construct an integrated indicator of green infrastructure that combines factors like seasonal variation, foliation density (pollution dispersion), tree conditions (drivers' safety), etc.

In this study, air pollution removal quantification was based on place-specific literature, and no information was found about air pollution removal by species in Strasbourg city. This information could be provided by the new version of i-Tree Eco which requires an update of the assessment study. Other factors could also be integrated into the routing-system, like seasonal variation, management practices, etc., as means of enhancing the model and simulation presented here.

i-Tree Eco V5 quantified air pollution removal rates based on an urban forest survey in Strasbourg city that was conducted in 2013 and local data collection (hourly weather data and pollution data). To make the implementation of the smart-routing system more efficient at the micro-scale (i.e., roads), a network of sensors could be set up at road level to measure traffic and pollution generated by the transport network. Thus, in-depth analyses are necessary to develop bottom-up simulation models to study the local dispersion conditions and study the impact of trees at the local scale.

Further research focusing on integrative approach is recommended because we recognize the complexities of taking into account all subsystems of a city system. With regards to green infrastructure, more information on green infrastructure, such as impact on proximity of schools, crashes, and potential flooding risks, etc., are interesting points that could be explored in future work.

While the presented methodology focused on responding to the main objective and took as a starting point combined mobility information obtained through a smart routing system and environmental information focusing on green infrastructure to enrich information delivered to citizens, possible further development of the methodology would focus on advanced development of the smart routing system by considering historic data and more factors such as characteristics of routes and traffic performance measures of routes, etc. Various factors can affect emissions by vehicles, such as speed, congestion level, etc., and could be taken into consideration in the future. Multivariate regression analysis could be used, and more parameters could be included, and their significance tested to analyse their influence on the selected route.

\section{Conclusions}

Mitigating urban challenges is increasingly becoming very important as urban population expands. Transformation of traditional cities into smart cities is regarded as a potential solution, and many cities around the world have embarked on a journey of transformation from traditional cities into smart cities. Though the literature demonstrated that the concept can have multiple benefits, it also showed that the existing transformation approaches of traditional city systems needed solid and integrative views to avoid disconnection of city subsystems. The proposed scenario in this work showed how a smart city system could be integrated by focusing on the information perspective and proposed an approach to mitigate air pollution through information integration in a smart city system. The work presented and justified the proposed vehicle smart routing system, a system that combined information from different smart subsystems of a smart city system to compute the least cost route and at the same time enhance information relevance. The combined information included mobility and environmental information.

Air pollution is one of the major challenges and its long-term health effects include fatal health diseases and global warming, which fuels natural disasters. The proposed technique, which combined and integrated information in a smart city, allows to provide information that helps to reduce air pollution.

The vehicle smart routing system showed that, while vehicle smart routing might not provide the fastest route, environmental cost, with special consideration of contribution to air purification processes, should be given good consideration and not only considered in terms of monetary or time costs. The results of the study showed that, in a scenario where there is consideration of environmental cost and air pollution removal capacity of each individual route, travellers would take different routes as opposed to routes proposed by other traditional eco-routing systems. However, much work remains 
to be done to achieve a mature system using a wider range of real time data and involving a complete set of all six subsystems of a smart city system as presented in Figure 1. Therefore, future work will consider real time information to take testing and validation of the proposed vehicle smart routing system to another level of accuracy and reliability.

Author Contributions: Conceptualization, J.M., T.B., and S.B.M.; methodology, J.M., W.S., and G.S.M.; software, J.M. and W.S.; validation, J.M., W.S., and G.S.M.; formal analysis, J.M. and T.B.; investigation, J.M.; resources, T.B. and M.C.; data curation, J.M. and W.S.; writing-original draft preparation, J.M.; writing-review and editing, J.M., T.B., S.B.M., K.B., G.S.M., and W.S.; visualization, J.M.; supervision, T.B., S.B.M., and K.B.; project administration, J.M. and T.B.; funding acquisition, T.B. All authors have read and agreed to the published version of the manuscript.

Funding: This research was funded by GLASGOW CALEDONIAN UNIVERSITY.

Acknowledgments: Many thanks to the Local Environment Management and Analysis (LEMA) unit (University of Liege) for making their infrastructure accessible to facilitate this research.

Conflicts of Interest: The authors declare no conflict.

\section{References}

1. Nations: World Urbanization Prospects: The 2014 Revision-Google Scholar. Available online: https://scholar.google.com/scholar_lookup?title=World\%20urbanization\%20prospects\%202014\&author= United\%20Nations\&publication_year=2014 (accessed on 30 July 2019).

2. Albino, V.; Berardi, U.; Dangelico, R.M. Smart Cities: Definitions, Dimensions, Performance, and Initiatives. J. Urban Technol. 2015, 22, 3-21. [CrossRef]

3. Huovila, A.; Bosch, P.; Airaksinen, M. Comparative analysis of standardized indicators for Smart sustainable cities: What indicators and standards to use and when? Cities 2019, 89, 141-153. [CrossRef]

4. Desdemoustier, J.; Crutzen, N.; Giffinger, R. Municipalities' understanding of the Smart City concept: An exploratory analysis in Belgium. Technol. Forecast. Soc. Chang. 2019, 142, 129-141. [CrossRef]

5. Dirks, S.; Keeling, M. A vision of smarter cities: How cities can lead the way into a prosperous and sustainable future. IBM Inst. Bus. Value 2009, 8. Available online: https://pdfs.semanticscholar.org/e46b/ 641d546a348df63762b8ce79b23911568f36.pdf (accessed on 30 July 2019).

6. Moss Kanter, R.; Litow, S.S. Informed and interconnected: A manifesto for smarter cities. Harv. Bus. Sch. Gen. Manag. Unit Work. Pap. 2009. [CrossRef]

7. Caragliu, A.; Del Bo, C.; Nijkamp, P. Smart cities in Europe. J. Urban Technol. 2011, 18, 65-82. [CrossRef]

8. Ojo, A.; Curry, E.; Janowski, T. Designing Next Generation Smart City Initiatives-Harnessing Findings and Lessons from a Study of Ten Smart City Programs. 2014. Available online: http://aisel.aisnet.org/ecis2014 (accessed on 30 July 2019).

9. Benevolo, C.; Dameri, R.P.; D'Auria, B. Smart Mobility in Smart City. In Proceedings of the Empowering Organizations; Torre, T., Braccini, A.M., Spinelli, R., Eds.; Springer International Publishing: New York, NY, USA, 2016; pp. 13-28.

10. Giffinger, R.; Gudrun, H. Smart cities ranking: An effective instrument for the positioning of the cities? ACE Archit. City Environ. 2010, 4, 7-26. [CrossRef]

11. Fernandez-Anez, V.; Fernández-Güell, J.M.; Giffinger, R. Smart City implementation and discourses: An integrated conceptual model. The case of Vienna. Cities 2018, 78, 4-16. [CrossRef]

12. Appio, F.P.; Lima, M.; Paroutis, S. Understanding Smart Cities: Innovation ecosystems, technological advancements, and societal challenges. Technol. Forecast. Soc. Chang. 2018. [CrossRef]

13. Abhijith, K.V.; Kumar, P. Field investigations for evaluating green infrastructure effects on air quality in open-road conditions. Atmos. Environ. 2019, 201, 132-147. [CrossRef]

14. Coloma, J.F.; García, M.; Wang, Y.; Monzón, A. Environmental Strategies for Selecting Eco-Routing in a Small City. Atmosphere 2019, 10, 448. [CrossRef]

15. Boriboonsomsin, K.; Barth, M.J.; Zhu, W.; Vu, A. Eco-Routing Navigation System Based on Multisource Historical and Real-Time Traffic Information. IEEE Trans. Intell. Transp. Syst. 2012, 13, 1694-1704. [CrossRef]

16. Scora, G.; Boriboonsomsin, K.; Barth, M. Value of eco-friendly route choice for heavy-duty trucks. Res. Transp. Econ. 2015, 52, 3-14. [CrossRef] 
17. Elliot, T.; Babí Almenar, J.; Niza, S.; Proença, V.; Rugani, B. Pathways to Modelling Ecosystem Services within an Urban Metabolism Framework. Sustainability 2019, 11, 2766. [CrossRef]

18. Baró, F.; Calderón-Argelich, A.; Langemeyer, J.; Connolly, J.J.T. Under one canopy? Assessing the distributional environmental justice implications of street tree benefits in Barcelona. Environ. Sci. Policy 2019, 102, 54-64. [CrossRef]

19. McPhearson, T.; Kremer, P.; Hamstead, Z.A. Mapping ecosystem services in New York City: Applying a social-ecological approach in urban vacant land. Ecosyst. Serv. 2013, 5, 11-26. [CrossRef]

20. Selmi, W.; Weber, C.; Rivière, E.; Blond, N.; Mehdi, L.; Nowak, D. Air pollution removal by trees in public green spaces in Strasbourg city, France. Urban For. Urban Green. 2016, 17, 192-201. [CrossRef]

21. Anonymous Urban Mobility. Available online: https://ec.europa.eu/transport/themes/urban/urban_mobility_ en (accessed on 7 November 2019).

22. Barth, M.; Boriboonsomsin, K. Real-world carbon dioxide impacts of traffic congestion. Transp. Res. Rec. 2008, 2058, 163-171. [CrossRef]

23. Ebner, K.; Mattes, P.; Smolnik, S. Are You Responsible for Traffic Congestion? A Systematic Review of the Socio-technical Perspective of Smart Mobility Services. In Proceedings of the 52nd Hawaii International Conference on System Sciences, 2019, Honolulu, HI, USA, 8-11 January 2019.

24. Muvuna, J.; Boutaleb, T.; Mickovski, S.B.; Baker, K.J. Systems engineering approach to design and modelling of smart cities. In Proceedings of the International Conference for Students on Applied Engineering (ICSAE), Newcastle upon Tyne, UK, 20-21 October 2016; pp. 437-440.

25. Muvuna, J.; Boutaleb, T.; Baker, K.J.; Mickovski, S.B. A Methodology to Model Integrated Smart City System from the Information Perspective. Smart Cities 2019, 2, 496-511. [CrossRef]

26. Traffic in Strasbourg. Available online: https://www.numbeo.com/traffic/in/Strasbourg (accessed on 9 April 2020).

27. Dobbs, C.; Kendal, D.; Nitschke, C.R. Multiple ecosystem services and disservices of the urban forest establishing their connections with landscape structure and sociodemographics. Ecol. Indic. 2014, 43, 44-55. [CrossRef]

28. Iqbal, M.; Zhang, K.; Iqbal, S.; Tariq, I. A fast and reliable Dijkstra algorithm for online shortest path. Int. J. Comput. Sci. Eng. 2018, 5, 24-27. [CrossRef]

29. Xia, C.; Zhang, Y.; Liu, Y.; Lin, K.; Chen, J. Path planning and energy flow control of wireless power transfer for sensor nodes in wireless sensor networks. Turk. J. Electr. Eng. Comput. Sci. 2018, 26, 2618-2632. [CrossRef]

30. Gupta, N.; Mangla, K.; Jha, A.K.; Umar, M. Applying Dijkstra's algorithm in routing process. Int. J. New Technol. Res. 2016, 2, 122-124.

31. Ismagilova, E.; Hughes, L.; Dwivedi, Y.K.; Raman, K.R. Smart cities: Advances in research-An information systems perspective. Int. J. Inf. Manag. 2019, 47, 88-100. [CrossRef]

32. Wania, A.; Bruse, M.; Blond, N.; Weber, C. Analysing the influence of different street vegetation on traffic-induced particle dispersion using microscale simulations. J. Environ. Manag. 2012, 94, 91-101. [CrossRef]

33. Salmond, J.A.; Williams, D.E.; Laing, G.; Kingham, S.; Dirks, K.; Longley, I.; Henshaw, G.S. The influence of vegetation on the horizontal and vertical distribution of pollutants in a street canyon. Sci. Total Environ. 2013, 443, 287-298. [CrossRef]

34. Luccherini, A.; Gonzalez-Ollauri, A.; Mickovski, S.B. The Effect of Vegetation on Soil Polluted with Galligu: Phytostabilisation and Novel Approaches to Evaluate Soil Galligu Concentration. Environ. Geotech. 2020. [CrossRef]

35. Mickovski, S.B. Risk-based framework accounting for the effects of vegetation in geotechnical engineering. CE/Papers 2018, 2, 377-382. [CrossRef]

(C) 2020 by the authors. Licensee MDPI, Basel, Switzerland. This article is an open access article distributed under the terms and conditions of the Creative Commons Attribution (CC BY) license (http://creativecommons.org/licenses/by/4.0/). 